\title{
Effect of Methods of Processing Groundnut (Arachis hypogaea L.) on the Susceptibility of the Seeds to Fungal Infection during Storage
}

\author{
R. E. Baraka ${ }^{1}$ and M. D. Tobin-West ${ }^{2}$ \\ ${ }^{1}$ Department of Crop and Soil Science, Niger Delta University \\ Wilberforce Island, Bayelsa State, Nigeria \\ ${ }^{2}$ Department of Crop/Soil Science, Rivers State University \\ Port Harcourt, P.M.B 5080, Rivers State, Nigeria \\ *Corresponding author's email: maureentobinwest [AT] gmail.com
}

\begin{abstract}
The study on the effect of storage length on susceptibility of variously processed and unprocessed groundnut seed to fungal infection were carried out in the Department of Crop and Soil Science laboratory. Four methods of processing (oil fried, sand fried, oven fried, smoked with seeds in shell) and a control (raw unprocessed seeds) was adopted and laid out in a Completely Randomized Design (CRD). Four fungal isolates were identified which are Aspergillus flavus, Aspergillus niger, Sclerotium rolfsii, and Fusarium moniliforme. Aspergillus flavus was the most pronounced fungi (41.35\%) followed by Aspergillus niger (38.15\%), Sclerotium rolfsii (34.92\%) and the lowest was Fusarium moniliforme (28.83\%). There was significant difference in fungal contamination at $5 \%$ probability level between the method of processing and raw seeds. Susceptibility to fungal infection revealed that oil fried seed were less susceptible to fungal invasion followed by smoked with seeds in shell, oven fried seeds, sand fried seeds and raw seeds. However, groundnut oil should be used to process groundnut seeds for human consumption because it stores better and is less susceptible to mycobial contamination. Also, controlled storage environment should be used to reduce fungal contamination, processing should be done in hygienic environment and seeds should not be stored for too long as the higher the storage period the more susceptible the seeds become.
\end{abstract}

Keywords--- Groundnut seeds, Fungi, storage and processing methods

\section{INTRODUCTION}

Groundnut (Arachis hypogaea L.) is an herbaceous leguminous crop of the New World, which originated in South America. Its dissemination to Africa, Asia, Europe and the Pacific Islands presumably occurred in the sixteenth and seventeenth centuries with the voyages of the Spanish, Portuguese, British and Dutch Groundnut is cultivated in nearly 100 countries on six continents between $40^{\circ} \mathrm{S}$ and $40^{\circ} \mathrm{N}$ of the equator (Gregory et al., 1973; Isleib et al., 1994).

Groundnut grows best in a well-drained sandy loam soil and the optimum soil temperature for its germination is $27^{\circ} \mathrm{C}$ $30^{\circ} \mathrm{C}$. The spacing for bunch varieties is $50 \mathrm{~cm} \times 20 \mathrm{~cm}$ or $75 \mathrm{~cm} \times 20 \mathrm{~cm}$ while semi-spreading varieties is $100 \mathrm{~cm} \times 20 \mathrm{~cm}$ or $75 \mathrm{~cm} \times 25 \mathrm{~cm}$ and the depth is $5 \mathrm{~cm}$, a depth deeper than this leads to elongated hypocotyls, poor shoot and root development, reduced yield (Ajeigbe et al., 2014). For normal development, it requires abundant sunshine and warmth (Stalker, 1997). Nigeria is the largest producing country in West Africa; it is mainly grown in the Northwest, Northeast and Central zones of Nigeria. It is the $13^{\text {th }}$ most important food crop of the world, $2^{\text {nd }}$ most important legume in the world after soybean based on production (FAO, 1994). Nigam (2004) reported that the parts of groundnut can be utilized in various ways as the shell is used for fuel, animal feed, cattle litter, filler in feed and fertilizer industry and in making particle boards and alcohol and acetone after fermentation, the haulm is used as animal fodder or in manuring; the roots fix nitrogen and organic matter to the soil, the seeds are rich in high quality edible oil (44-56\%), easily digestible protein (22-30\%), carbohydrates (10-25\%), vitamins (E, $\mathrm{K}$ and $\mathrm{B}$ complex), minerals ( $\mathrm{Ca}, \mathrm{P}, \mathrm{Mg}, \mathrm{Zn}$ and $\mathrm{Fe}$ ) and fiber.

Consequently, the seeds of groundnut can be processed in different forms: - can be processed into milk which can be used as a supplement to the diets of pre-school and school children, into groundnut chin-chin, groundnut cake, roasted groundnut, boiled groundnut, Yaji or ata suya, peanut butter, Donkwa, crushed for oil for edible and industrial uses, peanut flour for flavor enhancement and groundnut soup (Srilaskini 2003; Olayinka et al., 2013). Nonfood products such as soaps, medicine, cosmetics, pharmaceuticals, emulsion for insect control and fuels for diesel engines can be made from groundnut (Gibbons, 1980). Groundnut is also referred to as "woman's wealth or woman's treasure" in Gweza, Askira Uba, Damboa, 
Chibok and Biu Local Government Areas of Bornu State and Madagali, Michika and Hong Local Government Areas of Adamawa State, Nigeria (Olayinka et al., 2013).

However, fungal contamination on groundnut seeds occur both in the field and storage; in the field it retard the plant growth and also lead to reduce yield or plant death while in the store it releases chemicals (mycotoxins) which are harmful to the health of man and animals when consumed (WHO, 1987). Such fungi that cause qualitative and quantitative yield loss include Cercospora spp., Macrophomina phaseoli, Botrytis cinerea, Penicillium spp., Cladosporium herbarum, Sclerotium rolfsii, Aspergillus spp. (James, 1985). Godish (2001) stated that the toxins produced by the pathogenic fungi enters the blood stream and lymphatic system where they inhibit protein synthesis, damage macrophage system, inhibit particles clearance of the lungs and increase sensitivity to bacterial endotoxins. According to USDA (2010) rancidity is delayed by keeping nuts in air-tight container in the refrigerator or freezer as it helps extend shelf life of both processed and unprocessed groundnut seeds.

The aim of this research is to identify the fungi associated with the stored processed and unprocessed seeds, to know how the methods of seed processing affect fungal infection and to identify which method of processing stores better.

\section{MATERIALS AND METHODS}

\subsection{Experimental site}

The experiment was carried out at the laboratory of the Department of Crop and Soil Science, Faculty of Agriculture, Niger Delta University, Bayelsa State.

\subsection{Collection of Experimental materials and seed sorting}

Groundnut seeds were procured from the Bayelsa State Agricultural Development (ADP), Yenagoa. The variety of groundnut used was Samuru-38. The treatments used were: oil fried seeds, smoked seeds (smoking was done with seeds inside seed shell), oven heated seeds, Sand fried seeds, and raw seeds (control).

\subsection{Methods of processing the groundnut seeds}

\subsubsection{Oil fried method}

In this method, $4 \mathrm{~kg}$ of raw groundnut seeds was weighed into a 10 liter plastic container and 4 liters of boiling water was added into the content. Thereafter, $40 \mathrm{~g}$ of table salt $(\mathrm{NaCl})$ was sprinkled on the content for improved taste, which was stirred for 20 seconds with a wooden spatula in order to mix the salt thoroughly. After stirring, the content was covered with a lid and allowed to stand for 30 minutes. At the end of this period, the water was drained out and the seeds were transferred into a tray where hands were used to peel off the seed coats from the seeds.

These coatless seeds were then fried in 1 liter of well-refined boiling groundnut oil for 15 minutes and transferred from the boiling oil into a $5 \mathrm{~mm}$ iron sieve where the oil was allowed to drain out from the seeds. Completely drained seeds were transferred into a tray padded with soft napkin cloth to mop off any oil left on the seeds. Mopping off the oil lasted for 2 minutes after which the seeds were allowed to cool, transferred into a $75 \mathrm{cl}$ bottle, and covered with a tight cork for storage.

\subsubsection{Sand fried method}

In this method, $4 \mathrm{~kg}$ of raw groundnut seeds were weighed into a 10 liter plastic container and 4 liter of cold water was added into the content and allowed to stand for 20 minutes. At the expiration of this time, the water was poured out and $30 \mathrm{~g}$ of table salt $(\mathrm{NaCl})$ was sprinkled on the seeds and rubbed in until the seeds absorbed the salt. These seeds so salted were air dried for two hours and fried in $5 \mathrm{~kg}$ of fine river sand in iron pots for 30 minutes with constant stirring. Properly fried seeds together with the sand were removed from the pot, sieved in a $5 \mathrm{~mm}$ iron sieve, allowed to cool, transferred into a $75 \mathrm{cl}$ bottle and covered with a tight cork for storage.

\subsubsection{Oven treated methods}

This method is similar to that of sand fried; the only difference was that while sand fried used heated sand to fry seeds with local firewood, gas cooker or kerosene stove, oven treated involved placing the salted seeds in the oven ant the temperature regulated to $80^{\circ} \mathrm{C}$ for 20 minutes. At the end of the regulated time, the seeds were removed, allowed to cool, transferred into a $75 \mathrm{cl}$ bottle and covered with a tight cork for storage.

\subsubsection{Smoked with seeds inside shell}

This method of processing does not involve shelling the seeds. Here, $4 \mathrm{~kg}$ of unshelled pods were boiled in 6 liters of water for one hour and $60 \mathrm{~g}$ of table salt was added to the boiling content. After boiling, the pods were sieved out with a $5 \mathrm{~mm}$ sieve and the water allowed draining off. The pods were placed on a local altar and fire was used to smoke the pods to dryness for 24 hours. Properly dried pods were allowed to cool and kept in tightly covered $75 \mathrm{cl}$ bottles for storage. 


\subsection{Methods of groundnut seed storage}

Variously processed seeds and raw seeds were stored in glass bottles of $75 \mathrm{cl}$ capacity. Before storage, each bottle was washed thoroughly with detergent and sterilized in the oven at $65^{\circ} \mathrm{C}$ for 15 minutes. After sterilization, the bottles were allowed to cool before the seeds were stored in them.

\subsection{Isolation and incubation}

Ten (10) pieces of differently processed and unprocessed groundnut seeds were randomly assayed at every four (4) weeks. Such seeds were surfaced sterilized with ethanol and later washed with distilled water. The surface sterilized seeds were plated aseptically on Potato Dextrose Agar (PDA) and incubated at $28^{\circ} \mathrm{C}$ for 7 days. The fungal growths were sub-cultured to obtain pure colonies. The colonies were examined under the microscope for the spore characteristics, type of fruiting body, septation of hyphae and morphology/color of mycelia.

\subsection{Percentage incidence of fungi}

This was done to calculate the percentage of plants infected in the plant population. It was calculated thus:

$$
\frac{\text { No.of seeds infected with fungi }}{\text { Total no. of seeds assessed }} \times \frac{100}{1}
$$

\subsection{Experimental Design and Statistical techniques}

The experimental design used in this research is Complete Randomization Design and the treatments were replicated five times. Analysis of variance (ANOVA) was used to determine the treatment effects and means were tested using Least Significance Difference (LSD) at $5 \%$ level of probability (Wahua, 1999).

\section{RESULTS}

Table 1 identified four fungal species (Sclerotium rolfsii, Aspergillus niger, Aspergillus flavus and Fusarium moniliforme) responsible for invasion of stored groundnut seeds. The seeds that were variously processed had different levels of fungal infection in storage. Oil fried had the least infection and was resistant to Sclerotium rolfsii and Fusarium moniliforme, which was followed by oven fried seeds. Raw seeds and smoked with seeds in shell were high in Aspergillus flavus incidence, oven fried was high in Fusarium moniliforme incidence but low in Aspergillus niger, Aspergillus flavus and Sclerotium rolfsii incidences. There was no significant difference between sand fried and oven fried seeds in the incidence percentage of Aspergillus flavus, raw seeds and smoked with seeds in shell in Aspergillus flavus. Also, there was a highly significant difference $(\mathrm{p}<0.05)$ between the variously processed groundnut seeds in Sclerotium rolfsii and raw seeds had the highest fungal incidence rate in all the fungal species than the processed groundnut seeds.

The effect of length of storage on seed susceptibility clearly showed that Aspergillus flavus was more common in oven fried seeds followed by the sand fried seeds while Aspergillus niger was prominent in sand fried. Furthermore, sand fried seeds were found to have the highest incidence of Sclerotium rolfsii followed by the raw seeds while oven fried seeds had the highest incidence in Fusarium moniliforme. Though, there was significance at 5\% probability level between the variously processed seeds in the incidence of Aspergillus niger but no significant difference in the incidence rates between sand fried and smoked with seeds in shell in Aspergillus flavus as shown in Table 2 below.

Significant difference was recorded in the incidence rates of Aspergillus flavus and Fusarium moniliforme between the processed seeds after 12 weeks of storage. There was no significant difference between raw seeds and sand fried seeds in Aspergillus niger, between oven fried seeds and smoked with seeds in shell in Sclerotium rolfsii. In tables 4 and 5, Aspergillus flavus recorded the highest incidence rate compared to other fungi.

Table 1: Percentage incidence of fungi associated with the variously processed groundnut seeds (4 weeks after processing)

\begin{tabular}{lllll}
\hline Treatment & \multicolumn{3}{c}{ Fungi $(\%)$} & \\
\hline & A. flavus & A. niger & S. rolfsii & F. moniliforme \\
Raw seeds & 30.44 & 28.22 & 31.21 & 20.84 \\
Oil fried seeds & 7.64 & 7.14 & 0.00 & 0.00 \\
Sand fried seeds & 22.42 & 23.59 & 20.98 & 20.43 \\
Smoked seeds & 29.29 & 24.73 & 10.72 & 12.85 \\
Oven Fried Seeds & 22.34 & 20.20 & 26.42 & 21.79 \\
LSD $(0.05)$ & 1.36 & 1.60 & 1.08 & 1.43 \\
\hline
\end{tabular}


Table 2: Percentage incidence of fungi associated with the variously processed groundnut seeds ( 8 weeks after processing)

\begin{tabular}{lllll}
\hline Treatment & \multicolumn{5}{l}{ Fungi $(\%)$} & F. moniliforme \\
\hline & A. flavus & A. niger & S. rolfsii & 26.80 \\
Raw seeds & 32.80 & 31.90 & 42.22 & 0.00 \\
Oil fried seeds & 15.30 & 10.77 & 0.00 & 33.79 \\
Sand fried seeds & 36.49 & 40.32 & 43.05 & 21.97 \\
Smoked seeds & 36.35 & 34.00 & 30.72 & 38.32 \\
Oven Fried Seeds & 44.42 & 38.32 & 33.36 & 7.07 \\
LSD $(0.05)$ & 2.17 & 1.75 & 2.27 & \\
\hline
\end{tabular}

Table 3: Percentage incidence of fungi associated with the variously processed groundnut seeds (12 weeks after processing)

\begin{tabular}{lllll}
\hline Treatment & \multicolumn{5}{l}{ Fungi (\%) } & F. moniliforme \\
\hline & A. flavus & A. niger & S. rolfsii & 33.79 \\
Raw seeds & 41.13 & 43.82 & 46.31 & 0.00 \\
Oil fried seeds & 17.97 & 14.44 & 0.00 & 37.97 \\
Sand fried seeds & 49.55 & 45.85 & 51.54 & 24.90 \\
Smoked seeds & 48.06 & 39.05 & 44.32 & 42.72 \\
Oven Fried Seeds & 57.10 & 52.14 & 43.55 & 0.63 \\
LSD $(0.05)$ & 0.84 & 3.56 & 1.93 & \\
\hline
\end{tabular}

Table 4: Percentage incidence of fungi associated with the variously processed groundnut seeds (16 weeks after processing)

\begin{tabular}{lllll}
\hline Treatment & \multicolumn{5}{l}{ Fungi $(\%)$} & F. moniliforme \\
& A. flavus & A. niger & S. rolfsii & 50.52 \\
Raw seeds & 70.47 & 61.65 & 52.30 & 0.00 \\
Oil fried seeds & 21.28 & 18.84 & 0.00 & 43.84 \\
Sand fried seeds & 52.93 & 50.76 & 61.96 & 36.52 \\
Smoked seeds & 49.79 & 51.01 & 53.43 & 53.39 \\
Oven Fried Seeds & 60.22 & 58.01 & 48.69 & 1.43 \\
LSD $(0.05)$ & 0.81 & 0.56 & 1.44 & \\
\hline
\end{tabular}

Table 5: Percentage incidence of fungi associated with the variously processed groundnut seeds (20 weeks after processing)

\begin{tabular}{lllll}
\hline Treatment & \multicolumn{5}{l}{ Fungi (\%) } & F. moniliforme \\
& A. flavus & A. niger & S. rolfsii & 52.46 \\
Raw seeds & 80.02 & 69.07 & 55.10 & 0.00 \\
Oil fried seeds & 22.26 & 21.17 & 0.00 & 51.82 \\
Sand fried seeds & 70.38 & 51.32 & 63.54 & 36.79 \\
Smoked seeds & 53.40 & 53.37 & 60.78 & 59.31 \\
Oven Fried Seeds & 65.32 & 60.48 & 52.83 & 0.27 \\
LSD (0.05) & 1.15 & 2.00 & 0.93 & \\
\hline
\end{tabular}

\section{DISCUSSION}

The mycological assessment of the processed and unprocessed groundnut seeds is of utmost important to the human health as these pathogenic organisms degrade the quality and palatability of the groundnut seeds in storage. The four fungi species isolated in this research were among the fungi isolated by Baraka et al. (2010) who reported Aspergillus niger, Fusarium moniliforme, Aspergillus flavus and Sclerotium rolfsii amongst six fungi causing seed-borne infections on stored groundnut seeds. These fungi were also among the 10 severest mycoflora responsible for the worst groundnut production losses (Prasad, 1992). Previous findings by Fagbohun and Faleye (2012a) reported isolation of Fusarium spp., A. niger, A. flavus, A. fumigates, Penicillium spp. and Mucor spp. as the principal fungi degrading sundried groundnut seeds stored for twenty weeks. Species of Aspergillus, Penicillium, Fusarium, Rhizopus and Alternaria were found to be the common postharvest moulds in storage conditions (Chavan, 2011). These isolated fungi are evident that fungi enter and proliferate locally processed foods, also secretes mycotoxins which are harmful to man and animal health when consumed. 
The effects of length of storage on seed's susceptibility clearly showed that the longer the seeds were stored, the more susceptible they become. Oil fried seeds were resistant to the invasion of Sclerotium rolfsii and Fusarium moniliforme and also indicated least incidence rate of Aspergillus niger and Aspergillus flavus. This resistance is due to the fact that the oil used in processing the seed is a preservative and it has replaced the moisture content of the seed with oil thereby preserving the seeds against Fusarium moniliforme and Sclerotium rolfsii. Raw seeds had highest incidence of fungi contamination from the four isolated organisms than processed seeds in storage. However, sand fried seeds had the highest fungi incidence rate followed by oven fried seeds and the least is oil fried seeds in the effect of processing on fungi incidence rate. Aspergillus flavus was prominent in both the processed and unprocessed seeds and these findings corroborated with Ibiam and Egwu (2011) and Yu et al., (2004) who reported that Aspergillus flavus was the most preponderant species responsible for contamination of groundnut prior to harvest or during storage.

\section{CONCLUSION}

This study isolated four fungi that affect stored processed and unprocessed groundnut seeds; it also revealed that processing could reduce the susceptibility of seeds to mycoflora infection. The longer the seeds are stored the more susceptible the seeds become. Susceptibility to fungal infection revealed that oil fried seed were less susceptible to fungal invasion followed by smoked with seeds in shell, oven fried seeds, sand fried seeds and raw seeds. However, groundnut oil should be used to process groundnut seeds for human consumption because it stores better and is less susceptible to mycobial contamination. Also, controlled storage environment should be done to reduce fungal contamination, seeds should not be stored for too long as the higher the storage period the more susceptible the seeds become and processing should be done in hygienic environment.

\section{REFERENCES}

- $\quad$ Ajeigbe, H., Waliyar, F., Echekwu, C., Ayuba, K., Mutagi, B., Eniayeyu, D. \& Inuwa, A. (2014). A Farmer's guide to groundnut production in Nigeria. Patancheru 502 324, Telangana, India: International Crop Research Institute for the Semi-Arid Tropics, 36pp.

- Baraka, E. R., Onuegbu, B. A. \& Embiowei, S. E. (2010). Effects of Crude oil on the pathogenicity of Seed-borne Mycoflora of Groundnut (Arachis hypogaea L.). Acta Agronomica Nigeriana Journal, 10(1): 7-14.

- Chavan, A. M. (2011). Nutritional changes in oilseeds due to Aspergillus spp. J. Exp. Sci., 2: 29-31.

- Fagbohun, E. D. \& Faleye, O. S. (2012a). The Nutritional and Mycoflora changes during storage of groundnut (Arachis hypogaea). International Journal of Agronomy and Agricultural Research, 2(6):15-22.

- FAO (1994). Expert's recommendations on fat and oils in human nutrition. The article is adapted from the first chapter of fats and oils in human nutrition: report of joint expert consultation. FAO food and nutrition paper no 57.

- Gibbons, R.W. (1980). The ICRISAT groundnut program. Proceedings of the international workshop on groundnuts ICRISAT center, Patancheru, India, 13-17 October 1980: 12-16pp.

- Godish Thad (2001). Indoor environmental quality. Chelsea Mich: Lewis Publishers. pp 183-4.

- Gregory, W., Gregory, M., Krapovickas, A., Smith, B. \& Yarbrough, J. (1973).Structure and genetic resources of peanuts, pp.47-133. In: Peanut- culture and uses. Published by the Amer. Peanut Res. and Ed. Assoc., Inc. Stillwater, Oklahoma.

- Ibiam, O. F. A. \& Egwu, B. N. (2011). Postharvest seedborne diseases associated with the seeds of three varieties of groundnuts, (Arachis hypogaea L.) Nwakara, Kaki and Campalla. Agric. Biol. J. N. Am., 2(4): 598-602.

- Isleib, T. G., Wynne, J. C. \& Nigam, S. N. (1994). Groundnut breeding, in The Groundnut Crop: A Scientific Basis for Improvement, ed. Smartt J., editor. (London: Chapman and Hall), 552-623.

- James, G. D. (1985). Diseases of field crops. $3^{\text {rd }}$ Ed. Tata McGraw Hill Ltd. Bombay, New Delhi.

- Nigam, S. N. (2014). Groundnut at a glance. 121pp.

- Olayinka, B. U., Abdulrahaman, A. A., Andrauwus, Z. D., Aluko, T. A., Adebola, M. O. \& Oladele, F. A. (2013).Traditional preparations and uses of groundnut in Nigeria. Annuals Food Science and Technology 2014; 15(1): 29-34.Submitted 14.11.2013, Accepted 25.03.2014.

- Prasad, T. (1992). Detection of fungi in stored grains and estimation on mycotoxins in seed pathology. Proc. CTA Seminar held at Copenhagen, Denmark Tech Centre for Agric and Rural Co-operation.

- $\quad$ Srilakshimi, B. (2003). Food Science. $3^{\text {rd }}$ Ed. New Age International Publishers. 401pp.

- $\quad$ Stalker, H. T. (1997). Peanut (Arachis hypogaea L.). Field Crop Research 53: 205-217.

- USDA (2010). Refrigeration and food safety. Food safety in section service, May 2010.

- Wahua, T. A. T. (1999). Applied statistics for Scientific Studies. Tolukoya Print House, Ogun State, Nigeria. 362pp.

- World Health Organisation (WHO) (1987). Prevention of Liver cancer. Technical report, 691pp.

- Yu, J., Chang, P. K., Ehrlich, K. C., Cary, J. W. \& Bhatnagar, D. (2004). Clustered pathway genes in aflatoxin biosynthesis. Applied Environ. Microbiol., 70: 1253-1262. 